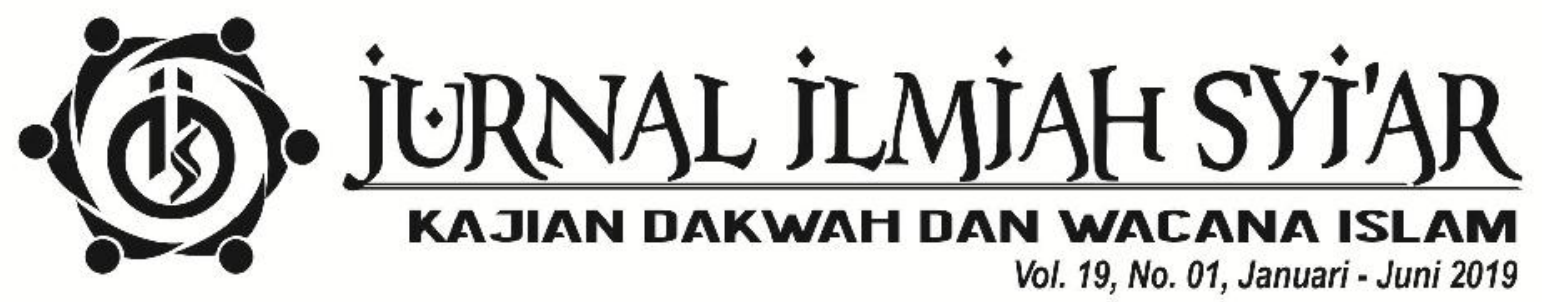




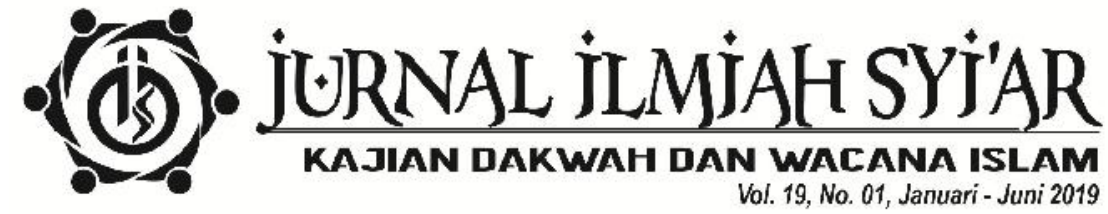

MITRA BESTARI

Khomsyahrial Romli (UIN Raden Intan Lampung)

Nelly Marhayati (IAIN Bengkulu)

Andi Dermawan (UIN Sunan Kalijaga Yogyakarta)

Bayu Mitra Aditya Kusuma (UIN Sunan Kalijaga Yogyakarta)

\section{PENANGGUNG JAWAB}

Suryani

REDAKTUR

Pebri Prandika Putra

EDITOR

Ihsan Rahmat

SEKRETARIS

Haqqi Annazili

DESAIN GRAFIS

Hymawandra

\author{
ALAMAT REDAKSI \\ Fakultas Ushuluddin, Adab, dan Dakwah \\ Institut Agama Islam Negeri Bengkulu \\ Jl. Jalan Raden Patah, Kelurahan, Pagar Dewa, Selebar, Pagar Dewa, Selebar, Kota \\ Bengkulu, Bengkulu 65144, Telp. \\ http:// ejournal.iainbengkulu.ac.id/index.php/syiar
}




\section{PENGANTAR REDAKSI}

Alhamdulillah, Jurnal Ilmiah Syi'ar, Vol. 19, No. 1 telah terbit tepat pada waktunya. Redaksi bersyukur ke hadirat Allah SWT atas seluruh karunia yang telah diberikan, baik yang terlihat ataupun kasat mata. Kemudian, shalawat beserta salam semoga tercurah bagi Nabi Muhammad SAW. Seorang rasul yang mempraktikkan berbagai metode dakwah bagi umat seluruh alam. Pada edisi ini, Jurnal Ilmiah Syi'ar (JIS) mengalami banyak pembenahan dalam rangka menuju akreditasi. Perubahan pertama datang dari ukuran jurnal cetak yang dianggap terlalu besar, sehingga redaksi memutuskan untuk menyesuaikan seukuran buku standar ISBN. Menetapkan waktu terbit dua kali dalam satu tahun, yakni edisi Januari - Juni diterbitkan pada Juni dan Juli - Desember diterbitkan pada Desember. Satu edisi berisi delapan jurnal berkualitas yang dikelola dengan sistem Open Journal System (OJS).

Pada edisi ini juga, redaksi bekerja sama dengan mitra bestari yang dinilai pakar pada salah satu fokus JIS, yaitu Komunikasi dan Penyiaran Islam, Manajemen Dakwah, Pengembangan Masyarakat Islam, Bimbingan Konseling Islam, dan Kesejahteraan Sosial. Selanjutnya, menyediakan logo khusus untuk JIS dengan tujuan mudah dikenali dan profesionalisme. Logo didesain dengan karakter tulisan 'JIS' berbentuk bulat bermakna bahwa Syi'ar Islam diperuntukkan bagi umat seluruh alam. Dakwah tidak membedakan suku, ras, agama, bangsa, dan negara. Kemudian, di luar karakter ada simbol orang yang saling bergandengan bermakna pola baru Syi'ar Islam di masa depan dengan model kolaboratif. Redaksi berpandangan bahwa kompleksitas kehidupan umat tidak mampu lagi diselesaikan dengan cara parsial atau metode dakwah perorangan.

Metode syi'ar Islam tidak mungkin dipisahkan dari sunnah Rasulullah SAW dan Khulafaur Rasyidin. Tulisan pertama mengangkat pembahasan tentang 'Manajemen Baitul Mal pada Masa Khalifah Umar Bin Khathab R.A: Sebuah Tinjauan Sejarah.' Fitmawati sebagai penulis tunggal telah banyak menulusuri proses terbentuknya baitul mal di madinah, sumber dana yang bisa menjadi pemasukan, tata cara pembagian, hingga hal teknis lainnya. Kajian ini ternyata juga mampu menjelaskan sistem ekonomi syariah di masa khalifah kedua. Tulisan kedua berupa pemikiran tentang konseling Islam berjudul 'Konselor dalam Penguatan Nilai dan Moral: Strategi Membentuk Generasi Religius' oleh Muahammad Nikman Nasir. Nasir mempertahankan argumen bahwa di era milenial, konselor membutuhkan nash-nash agama untuk membangun moral klien atau peserta didik. Agama menjadi titik tolak sebagai sumber kekuatan, agama sebagai budaya, dan agama sebagai konteks.

Ashadi Cahyadi mengisi slot ketiga dengan pembahasan 'Pembangunan dan Pemberdayaan Manusia melalui Dana Desa: Pola dari Masa Lalu hingga Sinergitas yang Rancu.' Asumsi studi ini adalah sinergitas infrastruktur diikuti dengan pemberdayaan masyarakat akan menghasilkan 
kesejahteraan yang berkelanjutan. Tetapi temuan mengatakan rasionalitas ini dinilai tidak berjalan bersamaan karena memberikan porsi yang besar untuk infrastruktur dan mengecilkan pemberdayaan manusia. Tulisan keempat milik Sifatul Aliyah dan Bayu Mitra A. Kusuma 'Tuntutan Kinerja dalam Keterancaman Kerja: Dilema Karir Penyuluh Agama Non-Pegawai Negeri Sipil.' Penulis banyak mengeksplor tentang keresahan penyuluh agama, langkah propaganda, hingga kebijaksanaan yang telah dikeluarkan pemerintah. Tulisan kelima berjudul 'Falsafah Huma Betang di Kalimantan Tengah: Sebuah Pergulatan Identitas Konselor Dayak Muslim' oleh Dody Riswanto. Dody menemukan konselor dayak muslim terbentur oleh persepsi negatif dari lingkungan sosial. Kemungkinan latar agama menjadi arus utama yang perlu dipertimbangkan untuk lingkungan Dayak yang rerata menganut agama berbeda. Penyelesaian Falsafah Huma Betang yang mengandung nilai-nilai toleransi dan saling menghargai antar pemeluk agama dinilai sebagai jembatan yang mampu mereduksi persepsi negatif.

Tulisan keenam berjudul 'Sumber Daya Manusia Koperasi Jasa Keuangan Syariah (KJKS) di Kota Padang: Dilema antara Pengelolaan dan Pemahaman Konsep.' M. Zaky Mubarak Lubis dan Netta Agusti menemukan bahwa 39\% pengelola KJKS belum memahami konsep dasar ekonomi Islam. Robeet Thadi menjadi penulis ketujuh dengan pembahasan 'Literasi Media Khalayak di Era Keberlimpahan Infomasi di Media Massa.' Ada pergeseran di era keberlimpahan informasi, yakni dari sulitnya mencari informasi menjadi sulitnya menyaring informasi. Thadi menekankan pentingnya kemampuan literasi media individu untuk melihat dan membedakan dunia nyata dan dunia yang diproduksi oleh media. Tulisan terakhir oleh Sugeng Sejati dengan judul 'Implikasi Egosentris dan Spiritual Remaja dalam Mencapai Perkembangan Identitas Diri.' Temuan utamanya adalah pengembangan identitas remaja yang egosentris dan spiritual ternyata menjadikan remaja tersebut memiliki prinsip dengan peran penting dalam kehidupan dan nilai dalam masyarakat.

Demikian catatan beberapa perubahan jurnal dan cuplikan dari isi JIS Vol. 19, No. 1. Redaksi menyadari bahwa masih terdapat berbagai kekurangan. Sehingga kritikan dan saran yang bersifat membangun sangat diharapkan demi penyempurnaan jurnal ini kedepannya. Akhirnya redaksi mengucapkan banyak terimakasih kepada berbagai pihak yang turut mendukung lahirnya edisi ini. Mulai dari para penulis yang setia merevisi berbagai kekurangan tulisan, para mitra bestari, tim redaksi yang bekerja maksimal, dan lainnya. Redaksi menunggu karya-karya terbaik penulis pada edisi berikutnya. Selamat membaca!!!

Pagar Dewa, Juni 2019 a.n TIM REDAKSI JIS Ihsan Rahmat 


\section{DAFTAR ISI}

$\begin{array}{ll}\text { Pengantar Redaksi } & \text { iii }\end{array}$

Daftar Isi

MANAJEMEN BAITUL MAL PADA MASA KHALIFAH UMAR BIN 1-29

KHATHAB R.A: SEBUAH TINJAUAN SEJARAH

Fitmawati

KONSELOR DALAM PENGUATAN NILAI DAN MORAL:

$30-42$

STRATEGI MEMBENTUK GENERASI RELIGIUS

Muahammad Nikman Nasir

PEMBANGUNAN DAN PEMBERDAYAAN MANUSIA MELALUI DANA

DESA: POLA DARI MASA LALU HINGGA SINERGITAS YANG RANCU Ashadi Cahyadi

TUNTUTAN KINERJA DALAM KETERANCAMAN KERJA: DILEMA

$55-67$

KARIR PENYULUH AGAMA NON PEGAWAI NEGERI SIPIL

Sifatul Aliyah, Bayu Mitra A. Kusuma

FALSAFAH HUMA BETANG DI KALIMANTAN TENGAH: SEBUAH

$68-76$

PERGULATAN IDENTITAS KONSELOR DAYAK MUSLIM

Dody Riswanto

SUMBER DAYA MANUSIA KOPERASI JASA KEUANGAN SYARIAH

$77-89$

(KJKS) DI KOTA PADANG: DILEMA ANTARA PENGELOLAAN

DAN PEMAHAMAN KONSEP

M. Zaky Mubarak Lubis, Netta Agusti

LITERASI MEDIA KHALAYAK DI ERA KEBERLIMPAHAN INFOMASI DI

90-102

MEDIA MASSA

Robeet Thadi

IMPLIKASI EGOSENTRIS DAN SPIRITUAL REMAJA

103-126

DALAM MENCAPAI PERKEMBANGAN IDENTITAS DIRI

Sugeng Sejati 


\title{
KONSELOR DALAM PENGUATAN NILAI DAN MORAL: STRATEGI MEMBENTUK GENERASI RELIGIUS ${ }^{1}$
}

\author{
M. Nikman Naser \\ Fakultas Ushuluddin, Adab, dan Dakwah \\ Institut Agama Islam Negeri Bengkulu
}

Korespodensi dengan Penulis:

M. Nikman Naser: Telp: 081379011421;

E-mail: nikmanmuhammad2015@gmail.com

Keywords:

Role of Counselors, Strengthening

Values. Moral,

Religious.

\section{Kata kunci:}

Peran konselor, penguatan nilai, moral, agama.

\begin{abstract}
Moral education is very important for learners to improve intelligence, emotional and spiritual. The value and moral learners to note because the education in school was very instrumental in supporting development of learners. Writing aims to provide information to teachers and counselors to instill the importance of moral values and the learners. Student often perform acts that violate the values and morals. Moral education aimed at guarding the learners do the wrong deeds in accordance with existing norms in society, the nation's moral decline that Indonesia is very good with high numbers in the teens, freesex, rampant use of illegal drugs, there was a brawl between students. This strategy is done the existence, responsibility, and yet how belief and practice againts those values need to be strengthened. Environment and peers influence the religious moral values in life. Counselors in terms in give it a role in shaping how to think, behave, and act to participant.
\end{abstract}

\begin{abstract}
Abstrak
Pendidikan moral sangat penting bagi peserta didik untuk meningkatkan kecerdasan, emosi dan spiritual. Nilai dan moral peserta didik perlu diperhatikan karena pendidikan di sekolah sangat berperan dalam mendukung pengembangan peserta didik. Menulis bertujuan untuk memberikan informasi kepada guru dan konselor untuk menanamkan pentingnya nilai-nilai moral dan peserta didik. Siswa sering melakukan tindakan yang melanggar nilai dan moral. Pendidikan moral yang bertujuan menjaga peserta didik melakukan perbuatan yang salah sesuai dengan norma yang ada di masyarakat, kemerosotan moral bangsa bahwa Indonesia sangat baik dengan jumlah remaja yang tinggi, sex bebas, maraknya penggunaan obat-obatan terlarang, terjadi
\end{abstract}

\footnotetext{
${ }^{1}$ Tulisan ini telah dipresentasikan dalam Seminar Nasional bertemakan "Penguatan Orientasi Nilai dalam Bimbingan dan Konseling sebagai Upaya Pengembangan Karakter Generasi Muda Indonesia", di Universitas Negeri Yogyakarta, November 2016.
} 
perkelahian antar siswa. Strategi ini dilakukan dengan keberadaan, tanggung jawab, dan bagaimana kepercayaan dan praktik terhadap nilai-nilai itu perlu diperkuat. Lingkungan dan teman sebaya mempengaruhi nilai-nilai moral keagamaan dalam kehidupan. Konselor dalam hal memberikannya peran dalam membentuk cara berpikir, berperilaku, dan bertindak kepada peserta.

\section{PENDAHULUAN}

Pendidikan merupakan pilihan strategis bagi suatu bangsa untuk bangkit dari keterpurukan. Begitupun bagi Indonesia, sudah menjadi keharusan untuk menempatkan pendidikan sebagai prioritas utama dalam pembangunan. Secara tegas upaya untuk menciptakan sumber daya manusia yang berkualitas tersebut tertuang dalam lembaran yuridis negara berupa Undang-undang tentang sistem pendidikan nasional. Melalui undang-undang Nomor 20 Tahun 2003 tentang Sistem Pendidikan Nasional, pemerintah mengusahakan dan menyelenggarakan satu sistem pendidikan nasional yang dapat meningkatkan keimanan dan ketakwaan kepada Tuhan Yang Maha Esa serta akhlak mulia dalam mencerdaskan kehidupan bangsa. $^{2}$

Fenomena runtuhnya solidaritas pendidikan moral di sekolah mau tidak mau kita harus memikirkannya. Secara teoritas dan faktual, pendidikan moral yang pertama dan utama adalah di rumah. Faktor pertamanya adalah lingkungan keluarga terlalu sempit sebagai tempat mendapatkan dan berlatih menerapkan nilai-nilai moral. Peserta didik pertama kali memperoleh nilai-nilai moralitas yang digunakan sebagai acuan diperoleh dari orangtua. Tetapi harus pula diakui bahwa menyerahkan pendidikan moral sepenuhnya kepada orangtua ternyata kurang memadai. Hal yang terjadi banyak orangtua masa kini hampir tidak punya waktu untuk mendidik anak-anak. Semua diserahkan sepenuhnya pada sekolah. Fakta disekolah seringkali nilai nilai yang diberikan guru lebih diikuti oleh anak-anak daripada orangtuanya. Faktor-faktor tersebut memberikan pendidikan moral menjadi sebuah imperatif bagi sekolah.

Semakin tingginya kasus amoral/asusila yang terjadi di Indonesia, mulai dari penggunaan narkoba, sampai dengan tawuran antar sekolah, seks bebas, dan berbagai kasus lainnya merupakan fenomena yang mengandung keprihatinan. Pada kondisi seperti ini, dunia

\footnotetext{
${ }^{2}$ Undang-Undang (UU) RI No. 20 tentang Sistem Pendidikan Nasional (SISDIKNAS)
} 
pendidikan menjadi sorotan. Pendidikan dinyatakan telah gagal mencetak generasi yang cerdas secara intelegensi, emosional, dan spiritual. Masalah ini seharusnya bukan dijadikan wacana perdebatan untuk menentukan siapa yang salah dan siapa yang harus bertanggung jawab, namun harus menjadi bahan pemikiran untuk mencari solusi tepat sebagai upaya mengatasinya.

Bagi sektor pendidikan khususnya konselor dalam hal ni, sudah saatnya membuat inovasi cerdas dalam sistem pendidikan. Suara kepedulian yang meneriakkan pentingnya diangkat kembali pendidikan moral dan budi pekerti yang sebaiknya diintegrasikan. Pendidikan sudah sejak zaman dahulu bertujuan untuk membentuk manusia yang utuh dan lengkap meliputi berbagai aspek. Pendidikan tidak hanya berorientasi pada aspek akademis semata dalam rangka penguasaan ilmu dan teknologi. Kemajuan teknologi dan ekonomi tidak menjamin hadirnya rasa bahagia di hati manusianya, malah dapat membawa dampak pada hilangnya jati diri dan makna kehidupan.

Pendidikan yang dikembangkan seharusnya seimbang antara kecerdasan intelektual, emosional, dan spiritual. Menghadirkan spiritualitas dalam pendidikan akan memberi makna besar terhadap kehidupan bangsa. Keyakinan terhadap keberadaan Tuhan akan menimbulkan komitmen kuat untuk selalu memberikan yang terbaik untuk bangsa. ${ }^{3}$ Internalisasi nilai-nilai moral religius dalam proses pembelajaran merupakan bagian penting yang perlu dikembangkan agar ilmu yang diperoleh peserta didik lebih bermakna.

Hakikatnya pembentukan nilai dan moral terintegrasi ke dalam proses pembelajaran kehdupan sehari-hari. Suatu hal yang perlu dipertimbangkan juga dalam konsep praksis lapangan menunjukkan bahwa dalam proses pendidikan secara umum mengutamakan target kurikulum mata pelajaran dan terfokus pada substansi. Beberapa hasil dari penelitian menemukan bahwa pembentukan nilai dan moral cenderung pada aspek koginitif. Adapun penilaian terhadap aspek lainnya, seperti aspek afektif dan psikomotorik belum optimal dilakukan.

\section{METODE}

Metode yang digunakan dalam peneltian ini merupakan studi pustaka atau gagasan yang masih besifat kajian teoritis. Studi kepustakaan merupakan teknik pengumpulan data dengan

${ }^{3}$ Ary Ginanjar Agustian, Peran ESQ dalam Peningkatan Kualitas Pendidikan. Pidato Dies Natalis ke-44 Universitas Negeri Yogyakarta, (Yogyakarta: UNY Press, 2008) 
mengadakan studi penelaahan terhadap fenomena lapangan, literatur-literatur, catatan-catatan dan laporan-laporan yang ada hubungannya dengan masalah yang dipecahkan. Studi ini dihasilkan dengan mencari sumber bacaan yang dinilai relevan, Kemudian membaca dan menyusun hasil bacaan ke dalam tabel menggunakan microsoft excel. Membaca interaktif memberikan kesempatan bagi kami untuk menggangkat intisari bacaan, kemudian menghubungkannya dengan pengetahuan yang telah dimiliki. Intisari bacaan kemudian disalin ke dalam tabel yang sebelumnya telah dibagi ke dalam beberapa kolom (sesuai kebutuhan, berisi kolom judul, penulis buku, intisari bacaan, halaman bacaan, kata kunci, kategorisasi, pentemaan). Terakhir mereduksi data hasil pembacaan atau intisari. Maksudnya adalah saat memasuki kerja pentabelan, penulis kembali membaca dengan seksama intisari bacaan guna memahami isi teks secara menyeluruh, melihat kesamaan atau perbedaan ide antar ahli, dan mempermudah penulis untuk melakukan tahap pentemaan.

\section{HASIL DAN PEMBAHASAN}

\section{Memaknai Nilai}

Value diartikan sebagai suatu konsep tentang apa yang dianggap seseorang penting dalam hidupnya. ${ }^{4}$ Value juga didefenisikan sebagai "apa yang diinginkan, apa yang di anggap baik, apa yang disukai, dan apa yang harus dilakukan". Nilai mencerminkan harapan, kehendak, tujuan keinginan moral. Nilai merupakan konstruk hipotesis, cerminan, kehendak, dan kekuatan pendorong. ${ }^{5}$

Menurut Kosasih nilai adalah sesuatu yang berharga baik menurut standar logika (benarsalah), estetika (Bagus-buruk), Etika (adil-tidak adil), agama (dosa,haram,dan halal) dan hukum (sah-absah), serta menjadi acuan atau sistem keyakinan diri maupun kehidupan ${ }^{6}$. Nilai adalah patokan-patokan yang berlaku dalam kehidupan masyarakat, misalnya adat kebiasaan dan sopan santun yang terkandung dalam pancasila adalah nilai-nilai hidup yang menjadi pegangan seluruh warga negara Indonesia. Definisi lain tentang nilai dikemukakan oleh Richard Merril 7, menurutnya nilai adalah patokan atau standar pola-pola pilihan yang dapat membimbing seseorang atau kelompok ke arah satisfaction, fulfillment, and meaning. Patokan

\footnotetext{
${ }^{4}$ Jack R. Fraenkel, How to Teach About Values: An Analytic Approach, (Prentice Hall, Inc., New Jersey, 1977).

5 Candida C. Peterson dan Michael Siegal, Mindreading and Moral Awareness in Popular and Rejected Preschoolers, The British Journal of Developmental Psychology, Vol. 20, No. 2, 2005. hlm. 205

${ }^{6}$ Robert L Gibson dan Mitchell H. Marianne, Bimbingan dan Konseling. (Yogyakarta: Pustaka Pelajar, 2011).

7 Djahiri Kosasih. Dasar dan Konsep Pendidikan Moral, (Jakarta: Departemen Pendidikan dan Kebudayaan Direktorat Jenderal Pendidikan Tinggi Proyek Pendidikan Tenaga Akademik, 1996).
} 
atau kriteria tersebut memberi dasar pertimbangan kritis tentang pengertian religius, estetika, dan kewajiban moral8.

Kesadaran tentang nilai perlu diterapkan kepada anak atau peserta didik secara khusus bermula dari masa prasekolah sampai masa sekolah ${ }^{9}$. Semua pihak termasuk orangtua, guru matapelajaran, konselor, pemerintah dan masyarakat perlu bekerjasama dalam menyemai sifat ini. Kesimpulannya, niai merupakan ide tentang apa yang oleh seseorang di anggap baik atau penting dalam hidupnya, sehingga dikehendaki, disukai, diinginkan, dan harus dilakukan. Oleh karena itu nilai menjadi pendorong dan pemandu perilaku seseorang.

\section{Moral}

Moral berasal dari bahasa latin mores yang berarti tata cara, kebiasaan, perilaku, dan adat istiadat dalam kehidupan ${ }^{10}$. Rogers mengartikan moral sebagai pedoman salah atau benar bagi perilaku seseorang yang ditentukan oleh masyarakat11. Simpton (dalam Allen) mengartikan moral sebagai pola perilaku, prinsip-prinsip, konsep dan aturan-aturan yang digunakan individu atau kelompok yang berkaitan dengan baik dan buruk. Moral menurut Piaget adalah kebiasaan seseorang untuk berperilaku lebih baik atau buruk dalam memikirkan masalah-masalah sosial terutama dalam tindakan moral ${ }^{12}$.

Moral adalah ajaran tentang baik-buruk suatu perbuatan dan kelakuan, akhlak, kewajiban, dan sebagainya. Dalam moral diatur segala perbuatan yang dinilai baik dan perlu dilakukan, serta sesuatu perbuatan yang dinilai tidak baik dan perlu dihindari. Moral berkaitan dengan kemampuan seseorang untuk membedakan antara perbuatan yang benar dan yang salah. Dengan demikian, moral juga mendasari dan mengendalikan seseorang dalam bersikap dan bertingkah laku.

Proses pembentukan perilaku moral menurut Kurtines dan Gerwitz melibatkan empat tahapan penting yaitu: (1) Menginterpretasikan situasi dalam rangka memahami dan menemukan tindakan apa yang mungkin untuk dilakukan dan bagaimana efeknya terhadap keseluruhan masalah yang ada, (2) Menggambarkan apa yang harus dilakukan dengan mengetrapkan suatu nilai moral pada situasi tertentu dengan tujuan untuk menetapkan suatu perilaku moral, (3) Memilih diantara nilai-nilai moral untuk memutuskan apa yang secara aktual akan dilakukan, dan (4) Melakukan tindakan yang sesuai dengan nilai-nilai moral.13

${ }^{8}$ I Wayan Koyan, Pendidikan Moral Lintas Budaya, (Jakarta: Dirjen Dikti, Depdiknas, 2000).

${ }^{9}$ Elizabeth B. Hurlock. Perkembangan Anak. (Jakarta: Erlangga, 1990).

${ }^{10}$ Doroty Rogers, The Psychology of Adolescence. (New Jersey: Prentice Hall, 1977).

11 Donal Allen, Rebecca F. Guy, Charles K. Edgley, Social Psychology as a Social Proces, (California: Wodworten Publishing Company, 1980)

12 Piaget, J. Psychology and Education (London: Hadder and Staunghton, 1976).

${ }^{13}$ Kurtines, W.W \& Gerwitz, J.L. (1992). Moralitas, Perilaku Moral, dan Perkembangan Moral. 
Kemajuan suatu negara dapat diukur dari keseriusan pemerintah memajukan pendidikan moral. Menurut David pemerintah Selandia Baru sangat mengedepankan pendidikan masyarakat di segala bidang. ${ }^{14}$ Namun yang paling utama adalah pendidikan moral yang harus diberikan kepada peserta didik. Perkembangan pendidikan moral di Selandia Baru termasuk yang terbaik di dunia.

Pendidikan moral merupakan prioritas utama karena memang tujuan pendidikan itu yaitu untuk memanusiakan manusia dan menjadikan manusia yang memiliki kepribadian utuh. Selain itu, dalam pendidikan tidak hanya memprioritaskan kemampuan kognitif (intelektual), namun juga afektif (sikap) dan psikomotor (keterampilan)15. Agar peserta didik memiliki moral yang baik dan terhindar dari pelanggaran-pelanggaran moral, maka perlu adanya kerjasama antara keluarga, sekolah dan masyarakat. Sebaik apapun pendidikan moral dalam keluarga tanpa adanya dukungan dari sekolah dan masyarakat, sulit bagi peserta didik untuk memiliki moral yang baik. Begitu juga pendidikan moral di sekolah, tanpa adanya dukungan dari keluarga dan masyarakat sulit untuk memiliki moral yang baik.

Dengan demikian, ketiga jenis lembaga ini tidak bisa dipisahkan dan harus saling mendukung. Model pendidikan nilai moral yang dapat diberikan kepada peserta didik di dalam keluarga, yaitu: (1) harus ditanamkan nilai-nilai agama sejak dini, yang diawali dengan pembinaan aqidah, dan (2) menanaman nilai-nilai akhlak sejak dini kepada anak-anak, seperti cara-cara berbicara, cara berpakaian, cara memilih teman, dan ditanamkan sifat-sifat yang baik. ${ }^{16}$ Model pendidikan nilai moral di yang dapat dilaksanakan di sekolah yaitu dengan cara menciptakan kultur religius di lingkungan sekolah kepada anak-anak. Jadi pendidikan itu idealnya tidak hanya mementingkan satu ranah intelektual saja namun juga dari segi sikap dan ketrampilannya. Pendidikan moral sangatlah perlu bagi manusia khususnya peserta didik, karena melalui pendidikan perkembangan moral diharapkan mampu berjalan dengan baik, serasi dan sesuai dengan norma demi harkat dan martabat manusia itu sendiri.

Menurut Kohlberg perkernbangan sosial dan moral manusia terjadi dalarn tiga tingkatan besar yaitu: (a) tingkatan moralitas prakonvensional, yaitu ketika manusia berada dalam fase perkembangan remaja awal, yang belurn menganggap moral sebagai kesepakatan tradisi sosial; (b) tingkat moralitas konvensional, yaitu ketika manusia menjelang dan mulai memasuki fase perkembangan masa remaja, yang sudah menganggap moral sebagai kesepakatan tadisi sosial; (c) tingkat moralitas pascakonvensional,

Penerjemah: M.I. Soelaeman. (Jakarta: UI Press).

${ }^{14}$ Thomas Lickona. Educating for Character, (Jakarta: Bumi Aksara 2015).

${ }^{15}$ Prayitno dan Amti, Erman, 2004, Dasar-Dasar Bimbingan dan Konseling, Jakarta: Rineka Cipta.

16 Tiffany, Nickles. 2011. The Role Of Religion And Spirituality In Counseling, PP-20-25 
yaitu ketika manusia telah memasuki fase perkembangan masa remaja dan pasca remaja (usia 13 tahun ke atas), yang memandang moral lebih dari sekedar kesepakatan tradisi sosial17. Untuk lebih jelasnya kita lihat table di bawah ini.

Tabel 1. Enam Tahap Perkembangan Pertimbangan Moral Kohlberg

\begin{tabular}{|c|c|c|}
\hline Tingkat & Tahap & Konsep Moral \\
\hline Tingkat 1 & $\begin{array}{l}\text { Moralitas prakonvensional } \\
\text { (usia 4-10 tahun) } \\
\text { Tahap 1: Memperhatikan } \\
\text { ketaatan dan hukum } \\
\text { Tahap 2: Memperhatikan pemu } \\
\text { asan kebutuhan }\end{array}$ & $\begin{array}{l}\text { Anak menentukan keburukan berdasarkan } \\
\text { tingkat hukuman akibat keburukan } \\
\text { tersebut; Perilaku baik dihubungkan } \\
\text { dengan penghindaran diri dari hukuman; } \\
\text { Perilaku baik dihubungkan dengan } \\
\text { pemuasan keinginan dan kebutuhan } \\
\text { sendiri tanpa mempertimbangkan } \\
\text { kebutuhan orang lain. }\end{array}$ \\
\hline \multirow[t]{3}{*}{ Tingkat 2} & $\begin{array}{l}\text { Moralitas konvensional (usia 10- } \\
13 \text { tahun) }\end{array}$ & $\begin{array}{l}\text { Anak dan remaja berperilaku sesuai } \\
\text { dengan aturan dan }\end{array}$ \\
\hline & $\begin{array}{l}\text { Tahap 3: } \\
\text { Memperhatikan citra"anak } \\
\text { baik" }^{\prime \prime}\end{array}$ & $\begin{array}{l}\text { patokan moral agar memperoleh } \\
\text { persetujuan orang dewasa, bukan untuk } \\
\text { menghindari hukuman; Pebuatan baik dan } \\
\text { buruk dinilai berdasarkan tujuannya. Jadi, } \\
\text { ada perkembangan kesadaran terhadap } \\
\text { perlunya aturan. } \\
\text { Anak dan remaja memiliki sikap pasti } \\
\text { terhadap wewenang dan peraturan; }\end{array}$ \\
\hline & $\begin{array}{l}\text { Tahap 4: Memperhatikan } \\
\text { hukum dan peraturan }\end{array}$ & Hukum harus ditaati oleh semua \\
\hline \multirow[t]{3}{*}{ Tingkat 3} & $\begin{array}{l}\text { Moralitas pascajonvensional (usia } \\
13 \text { tahun ke atas) } \\
\text { Tahap 5: Memperhatikan hak } \\
\text { perseorangan }\end{array}$ & $\begin{array}{l}\text { Remaja dan dewasa mendefinisikan } \\
\text { (mengartikan) perilaku baik sebagai hak } \\
\text { pnibadi sesuai dengan aturan dan patokan } \\
\text { sosial; }\end{array}$ \\
\hline & Tahap 6: & $\begin{array}{l}\text { Perubahan bukum dan aturan dapat } \\
\text { diterima jika diperlukan untuk } \\
\text { mencapai hal-hal yang paling baik; } \\
\text { Pelanggaran hokum dan aturan dapat } \\
\text { terjadi karena alasan-alasan tertentu. }\end{array}$ \\
\hline & $\begin{array}{l}\text { Memperhatikan prinsip- prinsip } \\
\text { etik }\end{array}$ & $\begin{array}{l}\text { Keputusan mengenai prilaku sosial } \\
\text { didasarkan atas prinsip moral pribadi } \\
\text { yang bersumber dari hukum uni versal } \\
\text { yang selaras dengan kebaikan umum dan } \\
\text { kepentingan orang Jain; Keyalcinan } \\
\text { terhadap moral pribadi dan nilai-nilai }\end{array}$ \\
\hline
\end{tabular}

17 Kohlberg, L. 1995. Tahap-tahap Perkembangan Moral, diterjemahkan oleh John de Santo dan Agus Cremers SVD, Penerbit Kanisius, Yogyakarta, Cetakan Pertama. 
tetap melekat meslcipun sewaktu waktu berlawanan dengan hukum

Yang dibuat untuk mengekalkan aturan sosial.

Sumber: Pengembangan penulis, 2018.

\section{Landasan Religius}

Landasan Religius bimbingan dan konseling pada dasarnya ingin menetapkan konseli sebagai makhluk Tuhan dengan segenap kemuliaannya menjadi faktor sentral upaya bimbingan dan konseling ${ }^{18}$. Landasan religius ini, terkait dengan upaya memasukkan nilai-nilai agama dalam proses bimbingan dan konseling. Pendekatan bimbingan dan konseling yang terintegrasi didalamnya dimensi agama, ternyata sangat disenangi oleh masyarakat Amerika. Kondisi ini didasarkan kepada hasil polling Gallup pada tahun 1992 yang menunjukkan:19

1. Sebanyak $66 \%$ masyarakat menyenangi konselor yang profesional, yang memiliki nilainilai keyakinan dan spiritual.

2. Sebanyak $81 \%$ masyarakat menyenangi proses konseling yang memperhatikan nilai-nilai keyakinan (agama).

Agama mempunyai pengaruh yang sangat besar terhadap kesehatan mental individu. Dengan demikian dapat dikatakan bahwa individu tidak akan mencapai atau memiliki mental yang sehat tanpa agama. Memberikan pelayanan bimbingan yang memasukkan di dalamnya nilai-nilai agama seharusnya mendapat perhatian dari para konselor atau pembimbing. Pendidikan agama harusnya diutamakan sebab dari agama terkandung nilai-nilai moral, etik dan pedoman hidup sehat yang universal dan abadi sifatnya.

Peran agama dalam upaya pemuliaan manusia mendapatkan tempat yang amat penting dan strategis. Dalam UUD 1945 menempatkan agama dalam sistem pendidikan nasional. Pentingnya peran agama yang dicerminkan dalam rumusan tujuan yang hendak dicapai oleh tujuan pendidikan dalam UU No 2/1989 tentang Sistem Pendidikan Nasional, yaitu menyangkut manusia yang beriman dan bertakwa terhadap Tuhan Yang Maha Esa. Kaitannya dalam pelaksanaan bimbingan dan konseling yang juga merupakan salah satu upaya pemuliaan kemanusiaan, juga diperankan kaidah-kaidah agama yang berkenaan dengan hakikat sasaran layanan (peserta didik), serta konteks sosial budayanya. Peran agama dalam

${ }^{18}$ Nur Azizah, 2016. Perilaku Moral dan Religiusitas Siswa Berlatar Belakang Pendidikan Umum dan Agama. Jurnal Psikologi, (33), No. 2, Hal.1-16.

19 Richards, P.S., \& Bergin, A. E. 1997. A spiritual strategy for counseling and psychotherapy. Washington, DC: American Psychological Association. 
bimbingan dan konseling diharapkan membentuk karakter siswa yang religius. Ada beberapa peran agama dalam kesehatan mental, antara lain:

1. Agama dapat memberikan bimbingan dalam hidup.

2. Aturan agama dapat menentramkan batin.

3. Ajaran agama sebagai penolong dalam kebahagiaan hidup.

4. Ajaran agama sebagai pengendali moral.

5. Agama dapat menjadi terapi jiwa.

6. Agama sebagai pembinaan mental.

\section{Hubungan antara Moralitas dan Agama}

Saat ini kita tinggal dalam masyarakat yang sangat heterogen dalam hal perbedaan agama, berikut terdapat tujuh poin yang mendasari hubungan antara moralitas dan agama diantaranya:

1. Kebanyakan orang di negara ini menganut agama dan memilki identitas yang cenderung berbeda beda. Bagi sebagian masyarakat bimbingan yang pertama dan utama dalam pembentukan moral adalah berlandaskan pada agama yang mereka anut.

2. Agama bagi kebanyakan orang merupakan acuan utama yang membawa mereka untuk membentuk kehiupan yang bermoral.

3. Melalui pandangan agama secara umum Tuhan adalah Maha pemberi pertolongan, yang Maha tinggi, dimana kita sebagai makhluk Nya memiliki kewajiba untuk melakukan perbuatan-perbuatan baik, seperti yang diperintahkan oleh Tuhan.

4. Para perintis negeri ini telah melihat adanya hubugan yang sangat dekat antara agama dan hak-hak asasi manusia serta sistem pemerintahan demokrasi.

5. Kebanyakan siswa bersikap acuh tak acuh terhadap peran agama dalam pembentukan moral dan pembangunan negeri.

6. Banyak sekali orang yang hidup beragama, tetapi tidak memilki yang berarti dalam kehidupan.

7 Langkah - langkah dalam mendefinisikan moral secara rasional yang dapat diterima oleh semua pihak didasarkan pada sebuah prinsip klasik tentang ketuhanan, gagasan dari dasar-dasar hukum moral. ${ }^{20}$

${ }^{20}$ Stander, V. , Piercy, F. , Mackinnon, D., \& Helmeke, K. 1994. Spiritually, Religion and Family Therapy: Competing or Complementary Worlds. American Journal of Family Therapy, 22(1), 27-41. 


\section{Peran Konselor dalam Penguatan Nilai dan Moral}

Setiap konselor sebenarnya memiliki kesempatan untuk dapat menerapkan nilai-nilai moral religius dalam pelaksanaan Bimbingan dan konseling di Sekolah. Konselor dapat menyisipkan nilai-nilai moral religius dalam setiap program. Penguatan dapat dilakukan konselor setiap memberikan layanan baik seacara individu maupun kelompok. Penyisipan nilai-nilai moal religius ini juga dapat dilakukan untuk setiap matapelajaran. Setiap guru pengampu matapelajaran dapat melakukan penguatan nilai-nilai moral religius. Hanya saja bagaimana bentuk penguatan nilai-nilai moral yang dilakukan masing-masing guru dan Konselor memiliki kekhasan. Penguatan nilai-nilai moral religius seperti ketaqwaan, kejujuran, keikhlasan, dan tanggungjawab bukan semata-mata menjadi tanggung jawab guru yang mengampu matapelajaran Pendidikan Agama21.

Keberanian untuk setiap saat menyisipkan nilai-nilai moral religius dalam proses belajar menjadi tantangan besar para guru matapelajaran dan Konselor. Semua itu dilakukan melalui suatu proses yang panjang. Tidak serta merta nilai-nilai moral religius ini akan menjadi nilainilai yang langsung terinternalisasi dalam diri peserta didik. Proses panjang itu tetap harus dilakukan agar para peserta didik memiliki pemahaman yang kuat terhadap nilai-nilai moral religius yang harus mereka implementasikan dalam kehidupan sehari-hari. Selain itu, perlu ada komitmen dan kerjasama antar guru pengampu mata pelajaran untuk menciptakan sistem atau suasana pembelajaran yang memungkinkan nilai-nilai moral religius tersebut dapat diterapkan dengan baik.

Richards dan Bergin menyatakan lima alasan untuk memasukkan penilaian spiritual dalam konseling. Pertama, penilaian spiritual membantu konselor untuk mendapatkan pemahaman yang lebih baik dari pandangan dunia klien. Kedua, konselor dibantu dalam hal kemampuan untuk menentukan jika orientasi religius sehat atau tidak sehat, Ketiga, penilaian spiritual membantu konselor untuk mengevaluasi apakah komunitas keagamaan atau spiritual klien merupakan sumber bantuan. Keempat, konselor bisa lebih baik dapat menentukan intervensi spiritual atau agama yang berguna bagi klien. Terakhir, penilaian spiritual membantu konselor dalam menentukan bagaimana penyajian masalah klien dan masalahmasalah yang terkait dengan spiritual22.

Setelah penerimaan dan penilaian spiritual telah dilakukan, konselor berusaha secara efektif menerapkan religiusitas dengan menggunakan teknik konseling keluarga (counseling

${ }^{21}$ Frame, M. W. 1996. A Social Constructionist Approach to Counseling Religious Couples. The Family Journal: Counseling and Therapy for Couples and Families, 4, 299-307.

22 Stander, V., Piercy, F., Mackinnon, D., \& Helmeke, K. 1994. Spiritually, Religion and Family Therapy: Competing or Complementary Worlds. American Journal of Family Therapy, 22(1), 27-41. 
family techniques) yang ada dan prinsip-prinsip spiritualitas dari agama yang dimiliki. Misalnya, pendekatan konstruktivis (membangun) sosial dapat membantu konselor untuk terbuka dan tidak menghakimi keyakinan spiritual dan religius klien dan pendekatan yang berfokus solusi dapat membantu klien untuk menerapkan solusi-solusi yang akan dicapai untuk melihat permasalahan saat ini ${ }^{23}$.

Religiusitas dapat diintegrasikan secara implisit atau eksplisit. Integrasi implisit tidak memperkenalkan isu-isu agama atau spiritual dalam konseling, juga tidak terang - terangan mengintegrasikan praktek - praktek atau sumber daya spiritual atau agama. Anderson dan Worthen memberikan beberapa contoh spesifik integrasi implisit untuk pengobatan klinis ${ }^{24}$. Pertama, mereka berpendapat bahwa konselor mendengarkan klien dari perspektif spiritual, mengubah cara konselor mendengar dan memikirkan masalah klien. mendengarkan spiritual ini mungkin melibatkan konselor memasuki sikap meditasi yang berfokus pada pernapasan, emosi, kognisi, dan gambaran visual yang hadir kedalam pikiran. Akibatnya, konselor harus lebih mampu untuk melihat hal-hal yang mendetail dalam ruang konseling, menginspirasi tanggapan unik klien, membersihkan diri dari ide-ide bergerak tentang diri mereka sendiri atau hubungan konseling, dan memberikan lebih banyak perhatian untuk klien. Selain itu, para peneliti menyarankan memvisualisasikan dan mengatakan, "Anda adalah orang yang dicintai" atau berdoa diam-diam kepada Tuhan agar dibeikan kekuatan lebih selama proses konseling.

Integrasi eksplisit mengelola isu-isu agama dan spiritual terang-terangan dan membuat penggunaan sumber daya spiritual dan keagamaan seperti doa, teks-teks suci, dan anjurananjuran. Watson menawarkan tiga cara memasukkan spiritualitas dan agama dalam konseling 25 . Pertama, ia menyarankan menggunakan "agama sebagai sumber kekuatan" yang memanfaatkan tradisi keagamaan atau spiritual dari keluarga untuk meningkatkan kesehatan dan pertumbuhan. Dalam jenis pertama ini integrasi eksplisit, konselor tidak perlu memiliki keyakinan yang sama dengan klien, tetapi harus terbuka terhadap nilai-nilai dan keyakinan dari klien yang berbeda. Konselor dapat menggunakan agama sebagai sumber kekuatan dengan berdoa dengan keluarga, menugaskan pekerjaan yang melibatkan praktik keagamaan dari tradisi klien, atau menggabungkan tokoh agama di sesi konseling. Kedua, Watson menyarankan menggunakan "agama sebagai Budaya" ketika seorang konselor berbagi

${ }^{23}$ Wolf, C., \& Stevens, P. 2001. Integrating Religion and Spirituality In Marriage and Family Counseling. Counseling and Values, 46 (1).

${ }^{24}$ Anderson, D., \& Worthen, D. 1997. Exploring A Fourth Dimension: Spirituality As A Resource for The Couple Therapist. Journal of Marital and Family Therapy, 23(1), 3-12.

25 Tan, S. Y. 2003. Integrating Spiritual Direction Into Psychotherapy: Ethical Issues and Guidelines. Journal of Psychology and Theology, 31, 14-23. 
keyakinan klien untuk bergabung cerita klien dan lebih memahami mereka. Terakhir, Watson menyarankan konselor menggunakan "agama sebagai konteks" dan mengintegrasikan religiusitas mereka sendiri ke ruang konseling untuk membantu klien merasa lebih diterima.

\section{KESIMPULAN}

Peran konselor dalam penguatan nilai moral dapat dilakukan dengan memasukkan religiusitas dalam pelaksanaan Bimbingan dan Konseling itu sendiri. Konselor dalam hal ini dapat menggunakan teknik family therapy dengan tiga asumsi dasar yaitu agama sebagai sumber kekuatan, agama sebagai budaya, dan agama sebagai konteks. Sehingga dengan penerapan dasar ini mampu menjadikan peserta didik/klien menjadi manusia yang menjunjung tinggi nilai dan moral dalam kehidupan sehari-hari.

\section{DAFTAR PUSTAKA}

Allen, Donal, Rebecca F. Guy, Charles K. Edgley, Social Psychology as a Social Proces, (California: Wodworten Publishing Company, 1980Ginanjar Agustian, Ary, Peran ESQ dalam Peningkatan Kualitas Pendidikan. Pidato dies natalis ke-44 Universitas Negeri Yogyakarta, Yogyakarta: UNY Press, 2008.

Anderson, D dan Worthen, D. Exploring A Fourth Dimension: Spirituality As A Resource for The Couple Therapist. Journal of Marital and Family Therapy, Vol. 23, No. 1, 1997.

Azizah, Nur, Perilaku Moral dan Religiusitas Siswa Berlatar Belakang Pendidikan Umum dan Agama. Jurnal Psikologi, Vol. 33, No. 2, 2016.

Fraenkel, Jack R, How to Teach About Values: An Analytic Approach, Prentice Hall, Inc., New Jersey, 1977.

Frame, M. W. A Social Constructionist Approach to Counseling Religious Couples. The Family Journal: Counseling and Therapy for Couples and Families, Vol. 4, 1996.

Gibson, Robert L dan Mitchell H. Marianne, Bimbingan dan Konseling, Yogyakarta: Pustaka Pelajar, 2011.

Hurlock, Elizabeth B, Perkembangan Anak. Jakarta: Erlangga, 1990.

Kosasih, Djahiri. Dasar dan Konsep Pendidikan Moral, Jakarta: Departemen Pendidikan dan Kebudayaan Direktorat Jenderal Pendidikan Tinggi Proyek Pendidikan Tenaga Akademik, 1996.

Koyan, I Wayan, Pendidikan Moral Lintas Budaya, Jakarta: Dirjen Dikti, Depdiknas, 2000.

Kurtines, W. W dan Gerwitz, J. L. Moralitas, Perilaku Moral, dan Perkembangan Moral. Penerjemah: M.I. Soelaeman. Jakarta: UI Press, 1992. 
Lickona, Thomas, Educating for Character, Jakarta: Bumi Aksara 2015

Peterson, Candida C. dan Michael Siegal, Mindreading and Moral Awareness in Popular and Rejected Preschoolers, The British Journal of Developmental Psychology, Vol. 20, No. 2, 2005.

Prayitno dan Erman Amti, Dasar-Dasar Bimbingan dan Konseling, Jakarta: Rineka Cipta, 2004.

Richards, P. S, dan Bergin, A. E. A spiritual strategy for counseling and psychotherapy. Washington, DC: American Psychological Association, 1997.

Rogers, Doroty, The Psychology of Adolescence. New Jersey: Prentice Hall, 1977.

Stander, V, Piercy, F, Mackinnon, D., dan Helmeke, K, Spiritually, Religion and Family Therapy: Competing or Complementary Worlds. American Journal of Family Therapy, Vol. 22, No. 1 1994.

Tan, S. Y. Integrating Spiritual Direction Into Psychotherapy: Ethical Issues and Guidelines. Journal of Psychology and Theology, 31, 2003.

Wolf, C dan Stevens, P, Integrating Religion and Spirituality In Marriage and Family Counseling. Counseling and Values, Vol. 46, No. 1, 2001. 